\title{
Food hygiene and travel at sea
}

\author{
BETTY C. HoBBs \\ O.St.J., D.Sc., F.R.C.Path., Dip. Bact. \\ M. J. Colbourne \\ M.B., Ch.B., F.R.C.P., F.F.C.M., \\ D.T.M. \& M., D.P.H. \\ P. E. MAYNer \\ M.D., Ch.B., D.Obst., R.C.O.G. \\ Food Hygiene Laboratory, Central Public Health Laboratory, Colindale Avenue, London \\ Department of Community Health, University of Hong Kong and \\ Cherry Orchard, Guarlford, Malvern, Worcs.
}

\begin{abstract}
Summary
The incidence of gastroenteritis on a passenger ship is reviewed and discussed in relation to the agents of infection from stool specimens, the bacteriological condition of food samples, and the practice of galley hygiene.
\end{abstract}

\section{Introduction}

The subject of traveller's diarrhoea is not new and papers by Rowe, Taylor and Bettleheim (1970) and Rowe (1973) have described conditions leading to and the agents giving rise to gastroenteritis in travellers. Roberts and Hobbs (1974) reviewed reported outbreaks of food poisoning in travellers. They emphasized the faults in preparation which could lead to a state of gross contamination of food served, and suggested precautionary measures both for those responsible for the preparation and storage of food and for the traveller.

There are many published accounts of food-borne illness arising from food eaten on ships (Parker, 1954; Hobbs, Ritchie and Ritchie, 1962; Morbidity and Mortality, 1974a and b; Center for Disease Control, 1973a); aeroplanes (Morbidity and Mortality, 1971; Peffers et al., 1973; Public Health Laboratory Service, 1973; Sutton, 1974); trains (Hart, Sherwood and Wilson, 1960; Chernenkoff et al., 1971), and roadside cafés (Roberts and Hobbs, 1974). In some, the agents of infection or intoxication have been found (Peffers et al., 1973; Public Health Laboratory Service, 1973; Sutton, 1974) in others only suspected.

An enquiry into the reason for an unusually high and sustained rate of gastroenteritis in passengers and crew on successive cruises of one large liner led to the investigations reported here.

The ship's record of infection was studied and an attempt made to assess the sources and agents of infection.
Gastroenteritis records were obtained from six cruises and two round-the-world voyages by this ship from October 1972 to June 1973. The figures referred only to those cases reporting to the surgeon; but indications were that the actual number of cases was considerably greater. Comparisons with other cruise ships having similar itineraries showed that the rate of infection on this ship was high, particularly for cruises to the West Indies; an attack rate of $14 \%$ on two West Indies cruises by this ship compared with a mean attack rate of $2.4 \%$ in three cruises to the West Indies by three other ships.

Analysis of the two West Indies cruises in October/ November 1972 and May/June 1973 by this ship revealed similar patterns of infection (Fig. 1). Scattered cases of diarrhoea and vomiting occurred early in both cruises; the case rate then fell until a few days before arrival at the West Indies, when cases again began to occur in association with increasing air temperatures reaching a peak just as or immediately after the ship passed the West Indies islands. Thereafter there was a fall in the number of cases as the temperature fell.

Many of the crew members who had been ill had not left the ship at any of the ports, indicating that a single point of infection was unlikely. Amongst the passengers, there had been no obvious implication of any one dining room, saloon or cabin. A slight bias towards the first class passengers may have merely reflected that they were more likely to consult the surgeon.

Scanty microbiological data from examination of previously returned passengers and crew indicated that Salmonella typhimurium, $S$. sandiego, $S$. agona, $S$. newington, Salmonella sp. and Shigella sonnei had been agents of infection on board the ship at various times.

There were three stages of investigation: (1) A short Iberian cruise in June 1973; (2) surveillance of 


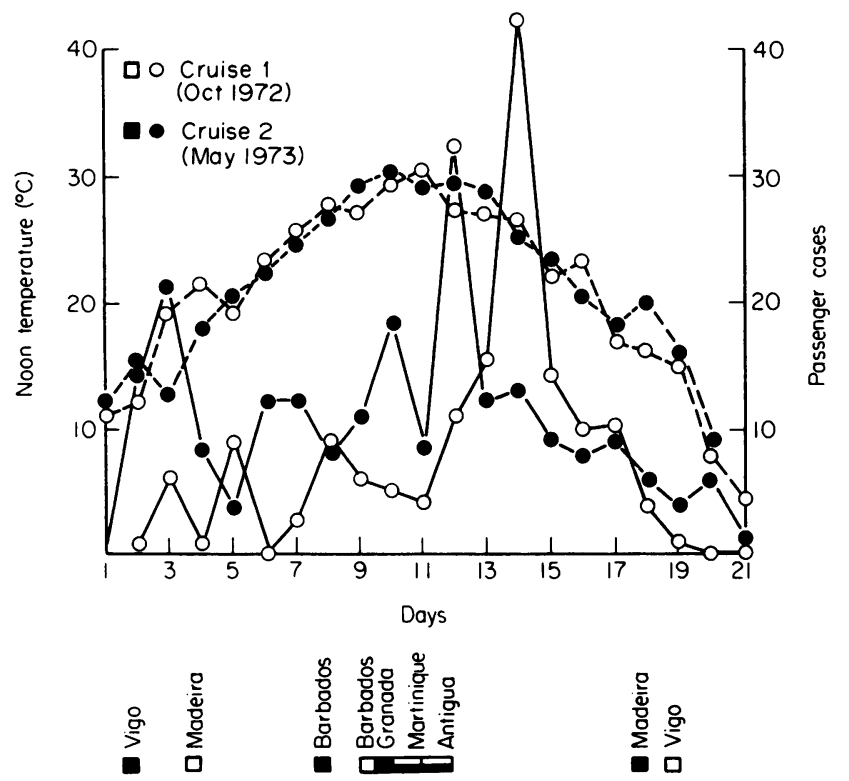

Fig. 1. Passenger cases, $\longrightarrow$, temperature, --- , and ports of call.

foods and faecal specimens taken during successive cruises (from June to November 1973) and collected when the ship docked in England; (3) a longer cruise to and through the Caribbean islands sailing home via Madeira in November 1973.

\section{(1) Iberian cruise, June 1973}

Repeated outbreaks of intestinal disease on the ship had been causing alarm for the previous 9 months. The short notice afforded by an urgent request for aid prevented adequate preparation and equipment and media were thereby limited; thus microbiological investigation was restricted.

Clinical details of gastroenteritis were obtained from thirteen patients who reported to the surgeon. Stool samples were cultured on board and foods were collected towards the end of the voyage for examination ashore. Poultry from the ship's suppliers was examined later.

Symptoms were similar to those recorded on previous cruises. They included diarrhoea alone, diarrhoea with vomiting or vomiting alone; abdominal pain and discomfort were frequently reported, but fever was rarely mentioned. Incubation periods were not established.

The pattern of irregular numbers of cases each day in this and other of the ship's cruises indicated day to day contamination of food items by errors in preparation and storage before consumptio Handling and environmental contamination was observed in the galley; the principal faults are described and discussed in the discussion section.

Water was provided from ports and from desalinized sea water. The port supply came from 2 quays and barges. Samples were tested for chlorine $\overrightarrow{\vec{O}}$ content and, when deficient, more chlorine was added to the tanks. Conscientious care of these duties was carried out. Contamination of food or water from? sewage was considered to be unlikely. There was not evidence that accidents leading to pollution had occurred on the cruises which had experienced a high level of sickness.

Stool examinations revealed little on this cruise; there was a single isolation of Salmonella typhimurium from a crew member who had been ill on a previous cruise. Subsequent bacteriological examina- $\rightarrow$ tion of foods indicated a high rate of Salmonella contamination in frozen chickens $(60 \%)$ and ducks $\mathrm{N}$ $(80 \%)$ and also in sausage-meat ( 2 of 3 samples); Salmonella contamination of turkeys was suspected 0 but not actually verified. Certain prepared foods $\omega$ ready for eating, such as cooked meats and sand-을 wiches, vegetable salads, mayonnaise and cream, had large bacterial counts including high levels of Escherichia coli and occasional Staphylococcus. aureus. The frozen Polish ducks examined from the 
ship had a high rate of contamination with Salmonella typhimurium. Frozen chickens subsequently examined from the English producer supplying the ship were heavily contaminated with $S$. senftenberg, and $S$. agona was isolated from packaged sausagemeat taken from the ship's store; this serotype had been isolated from patients diagnosed ashore after a previous cruise (Table 1).

TABLE 1. Salmonella isolations after voyage

\begin{tabular}{|c|c|c|c|}
\hline Food & $\begin{array}{c}\text { No. } \\
\text { examined }\end{array}$ & $\begin{array}{l}\text { Salm } \\
\text { No. } \\
\text { positive }\end{array}$ & $\begin{array}{l}\text { nonella spp. } \\
\text { Serotype }\end{array}$ \\
\hline $\begin{array}{l}\text { Chickens } \\
\text { (English) }\end{array}$ & 19 & $17(89 \%)$ & $\begin{array}{l}\text { S. senftenberg } \\
\text { S. saintpaul }\end{array}$ \\
\hline Ducks (Polish) & 21 & $18(86 \%)$ & $\begin{array}{l}\text { S. typhimurium } \\
\text { Salmonella sp. } \\
(\mathrm{O}=\text { rough, } \\
\mathrm{H}=\mathrm{i}, 12) \\
S . \text { derby }\end{array}$ \\
\hline $\begin{array}{l}\text { Sausage-meat } \\
\text { (packaged) }\end{array}$ & $\begin{array}{c}3 \\
\text { samples from } \\
\text { one packet }\end{array}$ & $2(66 \%)$ & S. agona \\
\hline
\end{tabular}

Efforts were made to improve the galley hygiene and the efficiency of food storage. Refrigeration and thawing of poultry were confined to rooms used for no other purpose than storage of poultry, and subsequent supplies of chickens, ducks and turkeys were obtained from different producers.

\section{(2) Surveillance of foods and faecal samples from June to November 1973}

Specimen containers were supplied to the ship together with culture media for ad hoc plating of stools by the medical staff who also recorded case details on a specially designed form. Culture plates, food samples and stool specimens were collected from the ship in England and fresh supplies of material were placed on board. The plates were often several days old before examination and sometimes suffered from inexpert plating out and cultures had not always been made from fresh specimens. Selenite liquid enrichment cultures made from stool specimens on the ship were plated out in the laboratory and all faecal specimens were re-examined for Salmonella, Shigella, Clostridium welchii and E. coli.

The number of cases was lower than in previous incidents; it may be significant that three of the cruises went to Scandinavia where the atmospheric temperature was low and that journeys to the Mediterranean were comparatively short.

The clinical symptoms were as before; a few sporadic cases occurred daily but there were no explosive outbreaks. Neither Shigella nor Salmonella were found in stool samples and $\mathrm{Cl}$. welchii was not found in significant numbers. Nine faecal samples were examined for viruses; picorna together with Coxsackie anti $A$ viruses were found in one sample of faeces only. A strain of $E$. coli which agglutinated with the antiserum to an 027 strain subsequently isolated from the November 1973 cruise, was found in the stools of nine out of nineteen and two out of nineteen persons with gastro-enteritis on the preceding two cruises.

Certain foods sampled during the surveillance period persistently showed high counts of mixed organisms including $E$. coli. An $E$. coli isolate from one sample of cream having a very high bacterial count agglutinated with the antiserum to the 027 strain referred to above. Examples of high and low counts from cold cooked meats and dairy products are given in Tables 2 and 3.

TABlE 2. Colony and Escherichia coli counts at $35^{\circ} \mathrm{C}$ in cooked meats

\begin{tabular}{lrc}
\hline Food & $\begin{array}{c}\text { Colony } \\
\text { count/g }\end{array}$ & E. coli/g \\
\hline Beef & & \\
1 & $7 \cdot 5 \times 10^{5}$ & $10-100$ \\
2 & $75 \times 10^{6}$ & $>100$ \\
Ham & $3 \times 10^{5}$ & $<10($ coliform $>100)$ \\
1 & $115 \times 10^{6}$ & $<10$ (coliform $>100)$ \\
2 & & $>100$ \\
Tongue & $4 \times 10^{5}$ & $>100$ \\
1 & $10 \times 10^{6}$ & $10-100$ \\
2 & & $>100$ \\
Chicken & $5 \times 10^{4}$ & 100 \\
1 & $45 \times 10^{6}$ & \\
2 &
\end{tabular}

TABLE 3. Colony and Escherichia coli counts at $35^{\circ} \mathrm{C}$ in dairy and egg products

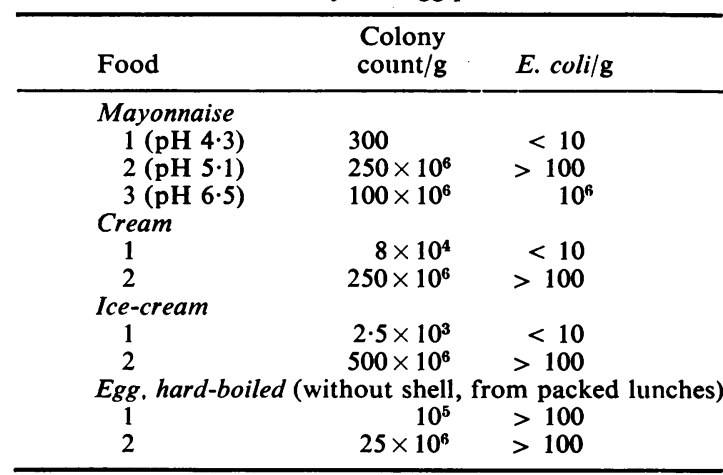

\section{(3) Caribbean cruise, November 1973}

With adequate time for preparation, more detailed microbiology on the ship was possible. Furthermore, the galley, and particularly the cold-storage facilities, were inspected $2-3$ times daily from the beginning of the voyage. Plating media included horse blood, MacConkey, deoxycholate citrate, 
brilliant green, xylose lysine deoxycholate (XLD) and thiosulphate citrate bile salt sucrose (TCBS) agars; the plates were stored in sealed plastic bags. Selenite $F$ in screw-capped bottles was used for selective enrichment.

\section{Faeces}

Stool samples were spread on each of the six agar media, and inoculated into selenite $F$, subcultured after $24 \mathrm{hr}$ on to MacConkey, deoxycholate citrate and brilliant green agars. Plates were examined after $24-48 \mathrm{hr}$ in an improvised incubator.

Slide agglutination using polyvalent sera for salmonellae and $E$. coli was carried out, but there was no provision for biochemical tests. Suspicious colonies of non-lactose and lactose-fermenting Gramnegative organisms and sweeps of lactose fermenters from apparently pure growth on MacConkey agar were stored on slopes of nutrient agar or dorset egg in small screw-capped bottles for examination ashore. Some anaerobic work was carried out using a BBL Gas Pak jar; incubation was at ambient temperature.

\section{Foods}

A large number of food samples were examined to obtain an approximate measure of the level of bacterial contamination. The foods were added, with or without previous chopping, to quarterstrength Ringer solution, sterile saline or distilled water in a plastic bag. The food suspension was shaken well and loopfuls plated out on to blood and MacConkey agars; growth levels were graded from \pm to ++++ . Plates of interest were held for further laboratory examination. Significant numbers of Staph. aureus were not noted on direct plates. No attempt was made to isolate salmonellae from these consumer foods, and by the time the food cultures were investigated it was known that salmonellae had not been found in stool samples from patients.

The resazurin test (Austin and Thomas, 1972) was used to estimate the approximate microbiological content of the foods. Resazurin solution was added to the suspensions of food and the colour change noted for the first few hours and overnight.

\section{Surfaces}

Swabs were moistened in Ringer solution and rubbed over the bottom surfaces of bowls and churns and over cutting boards; they were spread on the surface of blood agar plates and the amount of growth recorded after $24 \mathrm{hr}$. Plates with significant growth were subsequently examined in the laboratory ashore, as described for food cultures. Foods and swabs were mainly taken when the deck buffets were in progress and the atmospheric temperature high. It was assumed that care in handling and refrigera- tion might not be good at such times. Swabs were taken of receptacles, mostly polystyrene or othero synthetic materials, used for salad vegetables.

Results

Patients

Sixty-seven persons comprising fifty-nine passengers (predominantly tourist) and eight crew⿳亠口冋 reported sick, from forty-six of whom clinical de tails were obtained, listing diarrhoea.(45), vomiting (12), abdominal pain (36) and pyrexia (3) (Table 4).० The duration of illness varied from $2 \mathrm{hr}$ to 3 days, but two patients were unwell for 4 and 13 dayso respectively.

As on previous Caribbean cruises the incidence of gastroenteritis was higher as the ship sailed throughior the islands; some incidents might be attributed to shore meals. Table 5 gives the number of patients according to category of the patients and the posi-o tion of the ship at the time of the incidents.

TABLE 4. Caribbean cruise November 1973. Clinical datafrom forty-six patients and Escherichia coli 027 isolations

\begin{tabular}{lccc}
\hline Symptoms & No. of cases & $\begin{array}{c}\text { E. coli } 027 \\
\text { isolations }\end{array}$ \\
\hline Diarrhoea & 45 & 15 \\
Vomiting & 12 & None \\
Abdominal pain & 36 & 12 & None \\
Pyrexia & 3 & $\begin{array}{c}\text { 1- } \\
\text { Duration }\end{array}$ & 2 hr-7 days \\
& (mostly $1-2$ days) & (mostly 3 days) \\
\hline
\end{tabular}

TABLE 5. Recorded cases (67) and category and location of ship

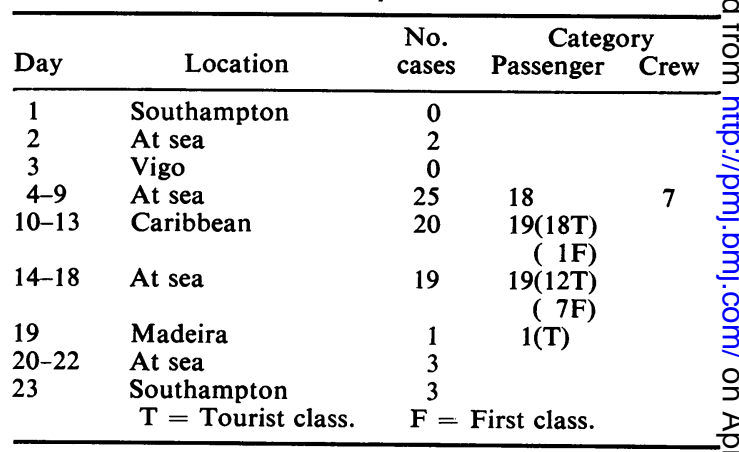

Stool samples were examined from thirty-eight patients. No faecal samples were examined from $\tilde{N}$ persons sick during the first 5 days which included N 2 days following landings at Vigo. Thereafter theyo were submitted before treatment was given and varied from fluid to soft to well formed; fluid samples usually contained mucus. A few direct? smears were examined microscopically for amoebae, $\tau$ Giardia and other parasites but none was seen. 
Organisms of the Salmonella and Shigella groups were not found but fifteen out of thirty-eight samples gave profuse (sometimes apparently pure) growth of $E$. coli 027 on MacConkey and other media not entirely inhibitory to $E$. coli. It was interesting to note that $E$. coli 027 was not isolated from stool specimens submitted by patients who had vomited.

$E$. coli 027 was first isolated from a passenger who submitted a sample on the seventh day. Two more isolations followed on the ninth day, one on the tenth and three on each of the eleventh, twelfth and thirteenth days. The general incidence of reported cases was higher over the period spent sailing and in making excursions in the warm and humid climate of the West Indies. Figure 2 shows the ports of call, the number of cases reported, the number of patients submitting stool samples and the $E$. coli 027 isolations during the voyage.

Of the fourteen passengers who described food they ate ashore, five were among those found positive for $E$. coli 027 ; they ate meals at the ports of Vigo, Trinidad, Grenada and Martinique but it is unlikely that infection with the same organisms had occurred at all four ports. Subsequent testing showed that the biochemical reactions of this isolate differed slightly from those of the other serotypes of $E$. coli found. The 027 strains gave strong positive reactions in the rabbit ligated loop test and in the suckling mouse test of Dean et al. (1972), while other serotypes isolated from the same and other patients were negative. More detailed results of the work done on this $E$. coli isolate will be published elsewhere. Mixtures of strains of $\mathrm{Cl}$. welchii (heat-resistant) were isolated from seven persons who suffered similar symptoms, two of whom were also excreting $E$. coli 027 . Those which were typable were from serotypes 5, 6, 11 and 18; two persons were excreting type 18 , and untypable strains were found in all seven.

It is difficult to assess the significance of the $\mathrm{Cl}$. welchii; the organisms could have been responsible for a proportion of the cases, as opportunities for germination of spores and growth during slow cooling or warming of meats and poultry were abundant. No other known food-poisoning agents of infection or intoxication were found, and none was isolated from patients who described vomiting amongst their symptoms. Some passengers had taken packed lunches ashore and possibly the sandwich fillings had developed high bacterial counts in the warm and humid weather. Others had eaten in restaurants ashore. It is also possible that other organisms not generally recognized as agents of food poisoning may cause nausea, vomiting and diarrhoea if consumed in large numbers. The possibility of viral gastroenteritis cannot be ignored (Editorial, 1974) but few virological studies were carried out. It should also be noted that the actual foods eaten by the patients were never available and estimations of incubation times were not possible.

\section{Food}

The amount of growth from a loopful of food suspension spread on a blood agar plate was estimated roughly and the colour change of resazurin noted. Cultures from cold cooked beef (open slices? and in sandwiches) varied from no colonies to confluent growth and the resazurin from a stable blue colour (little growth) to pink and colourless (heavy growth). On the whole the beef was more contaminated than other meats. Mayonnaise, potato and vegetable salads and cole slaw persistently showed

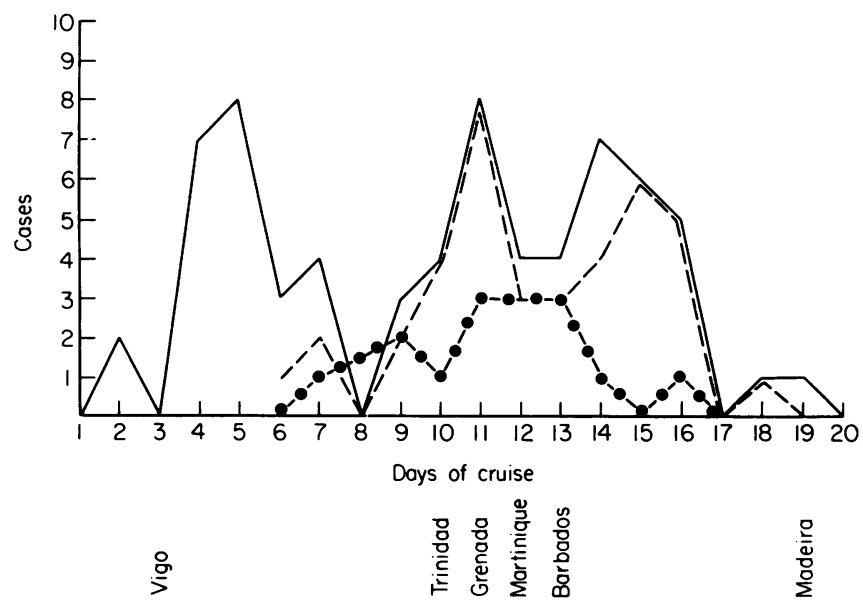

FIg. 2. Cases and E. coli 027 isolation during November 1973 cruise. - - Surgeon's case book; $-\ldots-$, faecal samples; - E. coli 027 isolations. 
heavy contamination with 4-plus growth on blood agar, mostly of Gram-negative organisms. There was profuse growth of Gram-negative organism from lettuce and green salad rinsings also. Swabs taken from 'clean' polythene and polystyrene containers in which salads were prepared and served gave profuse growth of organisms and presumably contributed a large initial contamination to foods put in them.

Swabs from some cutting boards and from churns, allegedly cleaned and steam-sterilized gave high counts. Many faults in hygiene were seen in the cold pantries used for preparation of salads and cold foods and facilities were inadequate particularly in the after-galley used for tourist food. Major faults were the small size of the preparation area where the cold room opened immediately into the pantry, the cold storage temperatures ranged up to $56^{\circ} \mathrm{F}$ in some other departments, foods such as vegetable, potato and green salads were prepared and stored in the contaminated polythene and polystyrene containers, soiled cloths were in contact with lettuce, hands and cutting boards, cold meats were lying on top of, or in close proximity to salads and other foods, and frozen cooked seafoods were allowed to thaw slowly in warm water in sinks or bowls which had been used for cleaning lettuce.

Pending transmission to the buffet sites, sliced meats for the tourist buffet were stored at ambient temperature while cold foods for first class passengers were stored under refrigeration, the hygiene of food handling being different in the two pantries. If enteropathogenic organisms were excreted by the pantry cooks, there was ample opportunity for spread and proliferation. E. coli was frequently isolated from food samples and swabs but on this voyage $E$. coli 027 was not found in food samples. Unfortunately the media and time available were insufficient for thorough food examination.

\section{Recommendations and discussions}

The following recommendations were made on the basis of faults observed:

\section{(a) Cold pantries}

More space and larger walk-in cold rooms with movable metal shelves were required. There should be refrigerated preparation benches in the galley, and a refrigerated table provided for the display of cold table foods in the restaurants. Refrigerator temperatures should be regularly checked.

\section{(b) Preparation}

All work areas, surfaces and equipment concerned with uncooked poultry or thawing of frozen poultry carcasses should be separated from those used for cooked foods.
Advanced cooking of poultry requiring more than $90 \mathrm{~min}$ of warm storage should be avoided. The cutting-up of cooked meat and poultry for the table is usually carried out in an overheated cooking area and therefore should be as rapid as possible.

Seafoods also need care, and cooked frozen prawns, for example, should be thawed slowly at a cold temperature. The handling of cooked foods and salad vegetables should be reduced to a minimum. The instruction to wash lettuce in chlorinated water should be observed properly.

Cream, milk, salad dressing or mayonnaise and sauces made-up in bulk should not be prepared more than 2 days ahead of requirements and should be well refrigerated.

Above all, cleanliness should be emphasized at all times in every aspect of the food service.

\section{(c) Ventilation and cooling facilities in the galley}

Air conditioning all over the galley was essential. There should be special cooling arrangements for $\stackrel{9}{工}$ food prepared in advance in bulk and eaten cold.

\section{(d) Buffets}

Cold modules (similar to those on large aircraf were desirable for cold food eaten on deck, with the size suitable for transport by lift. Delays, leading storage of food at ambient temperature, should be ov avoided. Metal trays and bowls should replace thos made of fibre and plastic materials.

\section{(e) Disposal of refuse}

A crusher or mixer was required for the disposal of refuse into the sea; the galley should not be used as a dumping area.

\section{(f) Equipment}

New apparatus was required for dicing and slicing vegetables; too much was done by hand after cooking. Steam jets should replace hose-pipes for sterilization purposes. Special measures for cleaning PVC pipes were required, and stainless steel bowls should be provided for vegetables, potato and green salads in place of plastic receptacles.

\section{(g) Menus}

These should be less ambitious, reduced in items and perhaps the same for tourist and first class passengers. Food for night snacks should be refrigerated carefully. In connection with this the Captain's cocktail parties, taking place usually on the second and third evenings after sailing, may, by placing an additional strain on the galley, have been associated with the groups of cases found to occur in the early stages of the cruises (Fig. 1 and 2). 
Eating ashore at ports such as Vigo, where there are many seafood restaurants, may have been another possible factor in these early cases.

(h) Sufficient time should be allowed between cruises for adequate cleaning of the galley and for the preparation of fresh food for joining passengers.

(i) More attention should be given to the cleaning and disinfection of mops, cloths, brushes and brooms, which ought to be stored clean and dry. Recommendations for sterilization by heat or disinfection by chemicals were given and a plea made for a reduction in the use of cloth materials which might spread agents of infection rather than remove them.

Attention to hygiene and cabin space in the crew's quarters is essential to avoid the spread of infection amongst the crew.

In a report on the use of plastics in connection with food, Wildbrett (1974) stated that whereas surfaces of metal and glass formed a tight barrier to foods, plastic surfaces may be penetrated. He quotes, as an example, the penetration of fat from milk into PVC tubing. Contrary to expectations, the amount of absorbed (immigrated) fat rose with high temperatures of cleaning solutions; furthermore, it was shown that the trapped fat could subsequently diffuse into the milk and that alkalinity exceeding pH 9 encouraged extraction of plasticizers from PVC tubes. It is possible that bacteria will penetrate plastics together with the fat. This indicates that cleaning should be carried out soon after use and that water and non-alkaline detergents should be used at temperatures not exceeding $50^{\circ} \mathrm{C}$.

The inference that a particular serotype of $E$. coli was pathogenic and that its intake with food gave rise to gastroenteritis in some persons needs critical assessment. There is no doubt that $E$. coli can spread and multiply in a variety of foods. Solodovnikov et al. (1974), using $E$. coli $\mathrm{M}-17$ as an indicator organism, deliberately infected one member of the crew and one food handler on each of a number of ships. After five days, the results of examination of faecal specimens from all the crew and washings from objects and equipment of kitchens, cabins and places of common use indicated that the food played by far the greatest role in the spread of infection.

There are three reports of $E$. coli 027 causing food poisoning in adults (Sakai et al., 1970; Sakazaki, Tamura and Nakamura, 1974; Shore et al., 1974). In the investigation described here $E$. coli 027 was the predominant organism from patients with diarrhoea but unfortunately, for practical reasons, it was not possible to examine the faeces from clinically unaffected persons as would have been epidemiologically desirable. The serotype was found on one occasion in cream but was not isolated from any other food. No other known intestinal pathogen was found. The appearance of $E$. coli 027 on more than one cruise is strong evidence for infection on board, but it is not certain whether it originated from food brought on to the ship or from the intestine of members of the galley crew. There was ample opportunity for the organism to multiply in the various foods and to be carried over from one cruise to the next. It is concluded that high counts in food of this particular serotype of $E$. coli was responsible for at least a proportion of the gastroenteritis cases and the recommendations are designed to reduce cross contamination and bacterial growth.

Coxsackie $\mathbf{A}$ and picorna viruses were found in one of the nine samples of faeces. According to Larkin (1973), if viruses are present in or on food the type and number present are directly related to the disease potential of the food. It is assumed that viruses would be easily transmitted and infective in small doses but, unlike bacteria, they do not multiply in food; the association that was found between increase of cases and temperature and humidity would not, therefore, be expected in a virus outbreak.

\section{Acknowledgments}

We are grateful to the Shipping Company for providing facilities for the investigation, to the staff of the Foods Hygiene Laboratory for examination of stool and foode samples, to Dr B. Rowe for serological typing of Escherichio coli strains, to Dr P. C. B. Turnbull for extensive editoriaf help, and to the Public Health Laboratory Service Board for leave of absence for B.C.H.

\section{References}

Austin, B.L. \& Thomas, B. (1972) Dye reduction tests on meat products. Journal of the Science of Food and Agriculture, 23, 542.

Center For Disease Control Shigella Surveillance (1973) Water-borne shigellosis on a Caribbean cruise. $34,9$.

Chernenkoff, W., Jellard, C.H., Toshach, S., Jones, S., Robertson, H.E. Chandhry, S., Wood, J., Park, C.E., ToDD, E.C.D. \& PivNick, H. (1971) Outbreak of staphylococcal food poisoning on a trans-Canada train. Epidemiological Bulletin, 15, 57.

Dean, A.G., Ching, Y.C., Williams, R.G. \& Harden, L.B. (1972) Test for Escherichia coli enterotoxin using infant mice: application in a study of diarrhoea in children in Honolulu. Journal of Infectious Diseases, 125, 407.

Editorial (1974) More about D and V. British Medical Journal, 4, 1.

Hart, C.J., Sherwood, W.W. \& Wilson, E. (1960) A food poisoning outbreak aboard a common carrier. Public Health Report. Washington, 75, 527.

Hobbs, B.C., Ritchie, J.M. \& Ritchie, E.D. (1962) Food hygiene on board ship. Journal of Hygiene. Cambridge, $60,259$.

LARKIN, E.P. (1973) The public health significance of viral infections of food animals. In: The Microbiological Safety of Food. Eds. B. C. Hobbs and J. H. B. Christian. London, Academic Press. p. 257.

Morbidity \& Mortality Weekly Report (1971) Gastroenteritis aboard planes. 20, 67. 
Morbidity \& MORTAlity WeEkly RePort (1974a) Survey of the incidence of gastrointestinal illness in cruise ship passengers. 23, 65 .

MORBIDITY \& MORTAlity WeEkLy RePORT (1974b) Salmonellosis on a Caribbean passenger cruise ship. 23, 70.

PARKer, W.S. (1954) Food-poisoning at sea. British Medical Journal, 2, 22.

Peffers, A.S.R., Bailey, J., Barrow, G.I. \& Hobbs, B.C. (1973) Vibrio parahaemolyticus gastro-enteritis and international air travel, Lancet, i, 143.

Public Health Laboratory Service (1973) Vibrio food poisoning on an aeroplane. British Medical Journal, 4, 117.

Roberts, D. \& HobBs, B.C. (1974) Feeding the traveller. Royal Society of Health Journal, 94, 114.

Rowe, B. (1973) The role of Escherichia coli in the diarrhoea of adults. 6th International Symposium of the World Association of Food-Hygienists. Elsinor, Denmark. August 1973.

Rowe, B., Taylor, J. \& Bettleheim, K.A. (1970) An investigation of traveller's diarrhoea. Lancet, $\mathbf{i}, 1$.

Sakai, S., Ito, T., Maruyama, T., SaIto, K. \& Zen-yoji, H. 1970) [Outbreak of acute enteritis ascribed to infection with Escherichia coli 027:K:H7.] Annual Report of the Tokyo Metropolitan Research Laboratory of Public Health, 22, 7. (Text in Japanese.)

Sakazaki, R., Tumura, K. \& Nakamura, A. (1974) Further studies on enteropathogenic Escherichia coli associated with diarrhoeal diseases in children and adults. Japanese Journal of Medical Science and Biology, 27, 7.

Shore, E.G., DeAN, A.G., Holik, K.J. \& Davis, B.R. (1974) Enterotoxin-producing Escherichia coli and diarrhoeal disease in adult travelers: A prospective study. Journal of Infectious Diseases, 129, 577.

Solodovnikov, Yu, P., Turchinskaya, M.V., Iorish, A.N., के Vilkovich, V.A., Osipov, Yu. V. \& KaZAK, N.D. (1974) A study of food and domestic routes of dysentery spread on river ships: a trial. Zhurnal mikrobiologii, epidemiologii i immunobiologii, 51, 90.

Sutron, R.G.A. (1974) An outbreak of cholera in Australia due to food served in flight on an international aircraft. Journal of Hygiene. Cambridge, 72, 441.

WildBretT, G. (1974) Cleaning problems with permeable plastic surfaces. IVth International Congress of Food Science and Technology, Madrid, September 1974. 